\title{
Titel/Title: Social Dimensions of Personal Growth following Widowhood: A Three-Wave Study
}

Autor*innen/Author(s): Claudia Recksiedler, Katharina Loter, Hannah S. Klaas, Betina Hollstein, Pasqualina Perrig-Chiello

Veröffentlichungsversion/Published version: Postprint

Zeitschriftenartikel/Journal article

\section{Empfohlene Zitierung/Recommended citation:}

Hollstein, Betina/ Klaas, Hannah S./ Loter, Katharina/ Perrig-Chiello, Pasqualina/ Recksiedler, Claudia (2018): Social Dimensions of Personal Growth following Widowhood: A Three-Wave Study. In: Gerontology, 64, 344-360.

Verfügbar unter/Available at:

(wenn vorhanden, bitte den DOI angeben/please provide the DOI if available)

"This is the peer-reviewed but unedited manuscript version of the following article: Hollstein, Betina/ Klaas, Hannah S./ Loter, Katharina/ Perrig-Chiello, Pasqualina/ Recksiedler, Claudia (2018): Social Dimensions of Personal Growth following Widowhood: A Three-Wave Study. In: Gerontology, 64, 344-360. The final, published version is available at http://www.karger.com/?doi=10.1159/000485916."

Zusätzliche Informationen/Additional information:

The author can be contacted at: betina.hollstein@uni-bremen.de 


\title{
Social Dimensions of Personal Growth followingWidowhood:AThree-Wave Study
}

\author{
Claudia Recksiedler ${ }^{\mathrm{a}}$ \\ KatharinaLoter ${ }^{\mathrm{b}}$ \\ Hannah S. Klaas ${ }^{\mathrm{c}}$ \\ Betina Hollstein ${ }^{\mathrm{d}}$ \\ Pasqualina Perrig-Chiello ${ }^{\mathrm{e}}$ \\ a Institute of Social Sciences and NCCR LIVES, University of Lausanne, Lausanne, Switzerland;

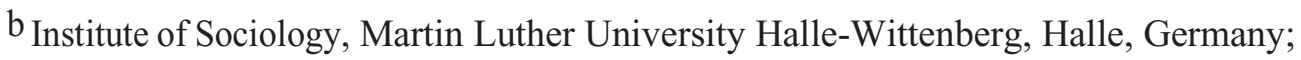 \\ c NCCR LIVES, University of Lausanne, Lausanne, Switzerland; \\ d Department of Sociology, University of Bremen, Bremen, Germany; \\ e Department of Psychology and NCCR LIVES, University of Bern, Bern, Switzerland
}

\section{Keywords}

Widowhood $\cdot$ Personal growth $\cdot$ Older adults $\cdot$ Social support $\cdot$ Social support seeking $\cdot$ Emotional support

\begin{abstract}
Background: Losing one's spouse is one of the most stressful life events in old age, yet research on positive consequences of overcoming critical life events describes experiences of personal growth for survivors. Objective: Because prior studies conceptualized personal growth as a stable accomplishmentof an individual, our study challenges this assumption by examining trajectories of personal growth and its links to two aspects of social support. We assume that personal growth is boosted by heightened levels of loss-related social support seeking during early years of widow- hood. However, toward the later stages in the bereavement process, we expect personal growth to be fostered by perceived social embeddedness. Data and Method: Data stem from a survey on relationships in later life conducted in 2012, 2014, and 2016 in Switzerland. The final analytical sample consisted of 508 individuals aged 50+ years, who were on average 73 years old and widowed for about 3 years at base- line. Longitudinal explorative factor analyses yielded a 3-factorial solution for personal growth. Random-effects groupspecific growth curves were used to examine the trajectories of personal growth and its subdimensions, by different levels of loss-related social support seeking and embeddedness in a supportive network, over the first 8 years of widowhood. Our analyses included time-invariant and time-varying co- variates. Results: On average, our findings point to a stable trajectory of personal growth after having become widowed in later life. Group-specific analyses, however, showed different courses in the trajectories for specific subdimensions of personal growth - particularly for spiritual change and appreciation of life. Average marginal effects also yielded group differences by loss-related support seeking in the level of personal
\end{abstract}


growth over time, which highlight the importance of social support seeking, rather than social embeddedness, at all stages of the bereavement process. Conclusion: Findings underline the importance of a longitudinal and linked-lives perspective on personal growth and point to different pathways regarding its various subdimensions. Future research should further examine the validity of personal growth scales for other populations and consider the possibility to experiencepersonal growth already during the anticipation of a traumatic event (e.g., in the case of long- term caretaking). $(\leftarrow \mathbf{p}$. 344)

\section{Introduction}

Losing one's spouse is one of the most stressful life events, which has been linked to detrimental effects on physical and mental health for the spouse that is left behind 1,2]. Yet, potential positive consequences following widowhood are understudied. For some individuals, the redefinition of identity and the adaptation to the new social role as widow(er) may lead to considerable gains in one's reorientation in life and a stimulation of personal development. This has been captured in the concept of personal growth (PG) or related constructs such as benefit finding, posttraumatic growth, or meaning making 3, 4]. At their core, all of these constructs operationalize PG as an individual achievement due to the critical life event, which is linked to successful coping and well-being during and after the event [5].

Prior studies have focused on individuals' characteristics and circumstances of a critical life event involved in the development of PG $[6,7,8]$. The factors contributing to PG on the contextual level, such as the availability of social support, and how this relationship develops over time, are less clear. Because being embedded in a supportive social network is an essential element of psychological adaptation to spousal bereavement $[9,10,11]$, our study aims to integrate social dimensions in the understanding of PG after spousal loss from a longitudinal perspective. Specifically, we examine how trajectories of PG vary by social support seeking and perceived social embedded- ness among a sample of widowed individuals aged 50 years and older.

\section{Spousal Bereavement as Critical Life Event}

Spousal loss is one of the most stressful life events throughout the life course, due to the loss of companion- ship, intimacy, and daily routines [2, 10, 12]. Subsequently, experiencing widowhood takes a toll on the physical health, emotional well-being, social integration, and the survivor's financial situation [1, 2 , 
$10,13]$. Nonetheless, the majority of bereaved individuals successfully adapt to spousal loss, and only a minor group suffers from enduring psychological impairment $[14,15]$. The effects of be- coming widowed, however, are not uniform across sociodemographic subgroups. For instance, the fact that widowhood is a more normative life event for older women [16], combined with the fact that they tend to cultivate stronger social ties, may explain that women seem better equipped to face this transition than men [17]. Social ties have proven to be a safety net of support in the adaptation to the new role as a widow(er) [18] and may ease the adaptation to the transition $[11,19]$. Even though networks are able to compensate the loss of a spouse to some degree with regard to emotional and instrumental support [10], the intimacy felt within a long- term marriage cannot be substituted [20]. Thus, the unique characteristics of the respective marital relation- ship and the circumstances surrounding the loss, such as the expectancy of the loss in case of long-term caretaking [21] or prior relationship quality [14], may influence individuals' adaptation to this new role.

\section{The Concept of PG}

Despite the long list of negative effects associated with spousal bereavement, there are also incidences of positive adjustment that transcend the normative recovery process $[3,13]$. Terms and definitions may vary across authors and disciplines (e.g., benefit finding, posttraumatic growth, or meaning making) [4, 6], yet the core concept of PG describes self-perceived positive changes related to struggling with a critical life event or a trauma. According to Tedeschi and Calhoun [22], PG comprises 5 subdimensions: changes in individuals' self-perception ("personal strengths"), philosophy of life ("appreciation of life"), improvements in personal relationships ("relating to others"), future outlook ("new possibilities"), and in- creased spirituality ("spiritual change").

Several predictors of PG have been identified in the literature including individual characteristics such as gender and personality [7] or the severity, type, and expectedness of the critical life event [6, 23, 24]. More specifically, age and gender differences emerged for changes on subdomains of PG following the onset of an illness [25]. Women seemed to report more growth on the factors "appreciation of life" and "spiritual change" com- pared to men, whereas younger respondents scored higher on "new possibilities" in contrast to older patients. Some studies investigating PG following cancer found that higher levels of education and income were related to higher levels of growth; however, findings have been inconsistent so far [26]. Lastly, there has been some evidence for a positive link between higher levels of growth and a range of patients' physical health outcomes, such as a more favorable disease progression. On the contrary, it is possible that more advanced stages of a disease can hinder the search for meaning, especially in domains of PG that concern 
future orientation. $(\leftarrow$ p. 345) Some scholars conceptualize PG as a process of coping with a difficult transition [5], whereas others see it as an outcome of dealing with the critical life event or both[22]. Most studies examining PG have adopted a cross-section- al study design or followed participants over a relatively short time span after the event. It is therefore unclear if levels of perceived PG during and after the event continue to increase, remain stable, or decrease over time. Across studies, results seem to suggest that the more severe the trauma is perceived, the higher the potential for PG seems to be [6]. Currier et al. [23], however, reported a curvilinear relationship between the strength of prolonged grief symptoms and PG, indicating that participants with intermediate grief symptoms were most likely to experience the highest levels of PG 2 years after the event.

\section{Widowhood, PG, and Social Support}

Prior research has shown that having a strong inter- personal support network is an essential protective factor in coping with bereavement $[9,11,13]$. The amount of social support following widowhood, however, seems to follow a clear progression over time. Guiaux et al. [27] reported that bereaved individuals received strong sup- port in the early phases of the transition. Yet, after 2-3 years of widowhood, individuals' social support networks shrunk to their pre-loss size. Furthermore, the death of a spouse is often associated with significant changes in the surviving spouses' friendships and social ties, which may result in reduced social networks and contacts [1]. Hollstein [10] showed that widowers who proactively expand and enrich their social networks through the engagement in novel activities and contacts reported higher levels of life satisfaction. Relatedly, Bookwala et al. [9] showed that widowers who had access to a friend as a confidante, to discuss private concerns, suffered less from depressive symptoms and displayed better physical health - comparable to those of continuously married individuals. The ability to mobilize new and existing social ties could, in turn, enhance the emergence of PG.

In a systematic review on bereavement and PG, Michael and Cooper [28] identified social support and demographic characteristics (e.g., gender) as moderators of PG. Particularly, social support is considered an important factor associated with PG, but results are mixed [26, 29, 30, 31], Certain types and aspects of support, such as emotional support and support satisfaction, seem to be more relevant for PG than others [31]. Ameta-analysis by Prati and Pietrantoni [30] further found that both social support and social support seeking contribute to the development of PG independently, yet potentially at different phases of the process. The underlying processes and the relationship between support seeking, social support, and PG, however, are complex and understudied. Evidence on the effects of gender on PG is also mixed. While some studies found 
that female respondents reported more growth [3], others suggested the contrary or no differences [24, 32, 33]. This study aims to address the research gaps concerning the scarce empirical evidence on long-term trajectories of PG among older individuals experiencing spousal bereavement, and the lack of studies accounting for group-specific trajectories by social sup- port and embeddedness.

\section{The Present Study}

This study contributes to prior research on spousal bereavement and PG in later life in two ways. First, in contrast to the majority of prior empirical studies, we examine longitudinal trajectories of PG and its subdimensions up to 8 years after the loss. Based on existing research, we expect that PG increases significantly during the early years of the bereavement process and then starts to de- crease slowly (Hypothesis 1). Second, we link PG to two aspects of social support - loss-related support seeking and perceived social embeddedness - that are expected to impact PG differently over time. We expect that actively seeking loss-related support within the social network impacts PG positively, especially at early stages of the grief process. In the first years after the event, individuals need help to cognitively work through the event and to rearrange their lives. Hence, seeking for loss-related sup- port aiming at overcoming the immediate consequences of the loss should contribute to PG. We therefore hypothesize that PG is only temporarily boosted by different levels of loss-related support seeking (Hypothesis 2a). In the subsequent waves, loss-related support seeking should become less relevant with regard to PG. In turn, a general sense of social embeddedness, as the perceived extent of potentially available social support, is thought to provide persons with possibilities to maintain the perceptions of positive changes and meaning in the long term. Hence, PG should then be influenced by different levels of social embeddedness into personal relationships, such as family ties, friendships, and acquaintances $($ Hypothesis $2 b) .(\leftarrow$ p. 346)

\section{Method}

\section{Data and Sample}

Data were derived from a longitudinal survey conducted in 2012, 2014, and $2016(n=2,857)$, which aimed at gaining insights into intimate relationships and marital dissolution or loss in middle and old age in Switzerland. Participants were recruited using arandom sample stratified by age, gender, and marital status supplied by the Swiss Federal Office of Statistics. In this study, we focused on the subsample of bereaved participants $(n=633)$. 
Out of this sample, we selected individuals aged 50 years or older, who were widowed for no longer than 8 years at Wave 1 of the survey and who lost their spouse after a marriage of 15 years and longer. The 517 widowers had experienced the loss of their spouse before $2012(n=492)$, or entered the survey in 2012 as longterm married participant and experienced spousal loss in between subsequent waves $(n=25)$. Nine participants were excluded be- cause of missing values on repartnering status and their perception of whether they had overcome the loss already in all 3 waves. The final sample consisted of 508 participants.

\section{Measures}

Dependent Variables

PG was assessed with the short form of the Posttraumatic Growth Inventory (PTGI), consisting of 10 items loading on 5 factors relating to others, new possibilities, personal strengths, appreciation of life, and spiritual change (2 items each) [34]. Participants were instructed as follows: "These questions assess whether certain things in your life changed due to the loss" (see Table 1 for items wording). Answers were given on a 6 -point scale $(0=$ not due to the loss I experienced, to $5=$ to a very high degree due to the loss I experienced).

Because the PTGI scale was validated for a US population, we verified the factorial structure of PG for the current sample using longitudinal explanatory factor analyses (EFA) in Mplus (Version 7.4). In all EFA models, we clustered by the person identifier (ID), specified oblimin rotation, and used a full information maximum likelihood estimator (FIML). The results yielded 3, rather than 5, subdimensions of PG: appreciation of life, personal strength, and spiritual change (Table 1). We removed the items of the unfitting subdimensions relating to others and new possibilities from our analyses and computed an overall mean score with the remaining 6 items, as well as mean scores for each subdimension of PG (see Cronbach's alpha for each subdimension in Table 2). We used all 4 mean scores ranging from 0 to 5 as continuous dependent variables in our subsequent analyses.

\section{Grouping Variables}

Because we were interested in group-specific differences in trajectories of PG and its subdimensions, we constructed distinct groups for 2 specific types of social support - loss-related support seeking and social embeddedness - that did not overlap and remained fairly stable overtime.

Loss-related support seeking was assessed by asking the respondents "What did you do (over the last 2 years) to cope with the new situation after the loss of your partner?". Participants could choose one or multiple of the following answers: "I tried to cope alone," "I sought support and comfort from the family," "I sought support and comfort from friends and acquaintances," "I sought support and comfort through spiritual 
guidance," or "I sought professional help (e.g., doctor or psychologist)." Based on the distinction between social versus solitary coping [35], we grouped the participants into 3 distinct categories of social support, namely: coped alone at all stages of the bereavement process (Group 0;n=102); network support seeking (either family, friends, professional help including spiritual guidance, or all of those) at all stages of the bereavement process (Group 1; $n=117$ ); and mixed support seeking (both coped alone and sought support within the social networks) at all stages of the bereavement process (Group 2; $n=289$ ).

A general sense of social embeddedness was measured using the 3-item social loneliness subscale from the De Jong Gierveld Loneliness Scale. The scale assesses individuals' evaluation of their social participation (or the lack thereof), which captures the degree to which respondents have a broader supportive network available that they can utilize and engage with [36]. The items were worded as follows: "There are enough people on whom I can rely in case of problems," "I know many people whom I can depend on," and "There are plenty of people with whom I feel closely connected." Answers were given on a 5-point Likert scale $(0=$ no, $1=$ rather no, 2 = more or less, 3 = rather yes, 4 =yes) with more than $75 \%$ saying "yes" or "rather yes" at all waves. Because there was only little variation in individuals' perception of social embeddedness over time, we computed mean scores over all 3 waves and used a median split (at 3.33) to classify the respondents into 2 distinct groups with either strong $(n=248)$ or weak social embeddedness $(n=260)$.

\section{Time-Invariant and Time-Varying Covariates}

Our analyses accounted for time-invariant covariates at event entry: age at widowhood (2 indicators: metric and 2 groups: $0=$ younger than 75 years [young-old adults], $1=75+$ years [old-old adults]), gender $(0=$ male, $1=$ female $)$, marital satisfaction $(0=$ very unhappy, to $9=$ very happy $)$, expectedness of the loss $(0$ = expected, 1 = unexpected $)$, educational attainment $(0=$ primary education, $1=$ secondary education, $2=$ tertiary education). We also included time-varying covariates: linear age, financial situation $(0=$ not enough money to support myself, 1 = enough money to support myself, 2 = more than enough money to support myself $)$, self-rated health $(0=$ very bad/bad, $1=$ so-so, $2=$ good, $3=$ very good $)$, repartnering $(0=$ single, $1=$ repartnered $)$, and current grief $(0=$ I am still coping with the loss, $1=$ I mentally overcame the loss).

\section{Longitudinal Character of the Data}

The dropout rate between Wave 1 (2012) and Wave 2 (2014) was 14.9\% and 18.5\% between Wave 2 (2014) and Wave 3 (2016). We ran logistic regressions to test whether our panel data were affected by attrition bias. There were no significant differences be- tween drop-outs and participants of the 3 waves with regard to 
all subdimensions of PG, gender, self-rated health, financial situation, education, marital satisfaction before the loss, and whether one has overcome the loss or not. In contrast, compared to baseline, older respondents $(\mathrm{OR}=$ $1.05, p<0.001)$ and those who were widowed for a longer period $(\mathrm{OR}=1.03, p<0.001)$ were more likely to drop out from the sample. There was also an attrition bias with regard to coping strategies. Respondents who coped alone and those who coped with their network were more likely to drop out from the sample than those who coped both alone and with their network $(\mathrm{OR}=1.93, p<0.05$, and $\mathrm{OR}=3.26, p<0.001$, respectively). The amount of valid values of PG and its subdimensions ranged from 428 to 448 in Wave 1, from 373 to 384 in Wave 2, and from ( $\leftarrow$ p. 347) 285 to 294 in Wave 3, with the lowest response rate for spiritual change. Because both the exact date of partner loss and the interview date were available in the data, we created the event time variable (widowhood duration) on a monthly basis first and then con- verted it to years following widowhood to ease interpretation. Our final dataset was in long format and consisted of 1,119 observations (unbalanced panel with a maximum of 3 observations per person) that were distributed as follows over time: $5 \%$ in the first widowhood year (up to 12 months), $5 \%$ in the second year (13-24 months), 17\% in the third year (25-36 months), 16\% in the fourth year (37-48 months), 22\% in the fifth year (49-60 months), 13\% in the sixth year (61-72 months), 14\% in the seventh year (73-84 months), $(\leftarrow$ p. 348) and $7 \%$ in the eighth year (85-96 months). Because we had fewer observations for the first 2 years as well as for the eighth year after the event, we advise caution while interpreting the results at the very beginning and the very end of the observed period. We highlighted this fact in our plots by adding 2 reference lines at Years 2 and 7.

\section{Analytical Plan}

We used group-specific growth curve models to examine trajectories of PG over time by support seeking and embeddedness, and to assess group differences in the level of PG at all stages of the bereavement process [37]. All models were estimated with the xtreg commands in Stata (Version 14.2). For theoretical reasons, a

cubic specification of event time was used that corresponds to the $(\leftarrow$ p. 349) duration of widowhood in years. We also used bootstrapped standard errors from 500 bootstrap samples in all of our models.

Our analytical strategy consisted of four steps. First, we examined the overall trajectory of PG with and without a constraint regarding the starting point of the process (Hypothesis 1). To decide whether to use fixedeffects or random-effects, we conducted and reported the Hausmantest(Table4). Second, we estimated a series of "empty" (i.e., unadjusted) random-effects group-specific growth curves with random intercepts for PG and its subdimensions (Table 5), including interaction terms between event time and time- invariant group indicators to model group-specific differential trajectories. We entered all group*(duration) interaction terms not as "standard effects" (e.g., i.group\#\#(time)), but as "nested effects" (e.g., i.group\#(time)). We then tested 
whether the shape of PG trajectories was similar across groups (Wald test for equal linear, quadratic, and cubic time paths) and whether the group differences in PG were significant at each widowhood year via postestimation tools (average marginal effects, AME). Third, we added time-in- variant covariates to the models and, fourth, time-varying covariates to trace final group-specific trajectories by 3 types of loss-related support seeking (Table 6) and 2 types of social embeddedness (Table 7; Hypotheses $2 a$ and 2b). Because Akaike's (AIC) and Schwarz's Bayesian (BIC) information criteria are not provided after the xtreg commands with random effects, we reported within and between $R^{2}$ values as the goodness of fit, which is common practice. $R^{2}$ within corresponds to the amount of explained variance of $\mathrm{PG}$ and its subdimensions with regard to intraindividual change over time, whereas $R^{2}$ between captures the amount of explained variance due to the differences between the respondents (e.g., due to different types of loss-related support).

Table 1. Longitudinal factor structure of personal growth (= p. 348)

Table 1. Longitudinal factor structure of personal growth

\begin{tabular}{llll}
\hline Items & $\begin{array}{l}\text { Factor 1 } \\
\text { Appreciation of life }\end{array}$ & $\begin{array}{l}\text { Factor 2 } \\
\text { Personal strength }\end{array}$ & $\begin{array}{l}\text { Factor 3 } \\
\text { Spiritual change }\end{array}$ \\
\hline New perspectives on priorities & $\mathbf{0 . 7 9}$ & 0.02 & 0.01 \\
New sense of importance of life & $\mathbf{0 . 9 2}$ & 0.00 & 0.01 \\
Greater understanding of spirituality & 0.06 & -0.06 & $\mathbf{0 . 9 7}$ \\
I know I can deal with difficulties & 0.10 & $\mathbf{0 . 7 7}$ & -0.04 \\
Stronger spiritual beliefs & -0.05 & 0.09 & $\mathbf{0 . 9 0}$ \\
I am stronger than I thought & -0.03 & $\mathbf{0 . 9 0}$ & 0.04 \\
\hline
\end{tabular}

Bold face indicates factor loadings of the respective factor. 
Table 2 (= p. 348)

Table 2. Sample description from a longitudinal perspective

\begin{tabular}{|c|c|c|c|}
\hline & \multicolumn{3}{|c|}{ Widowers in particular waves } \\
\hline & $\begin{array}{l}\text { Wave 1: } 2012 \\
(n=483)\end{array}$ & $\begin{array}{l}\text { Wave 2: } 2014 \\
(n=427 ; 16 \text { new })\end{array}$ & $\begin{array}{l}\text { Wave } 3: 2016 \\
(n=357 ; 9 \text { new })\end{array}$ \\
\hline \multicolumn{4}{|l|}{ Dependent variables } \\
\hline Amount of valid values & $<428-447>$ & $<373-380>$ & $<285-292>$ \\
\hline Personal growth & $2.54 \pm 1.29$ & $2.40 \pm 1.27$ & $2.18 \pm 1.23$ \\
\hline Cronbach's $\alpha(n)$ & $0.847(441)$ & $0.828(384)$ & $0.818(294)$ \\
\hline Appreciation of life & $3.01 \pm 1.47$ & $2.63 \pm 1.56$ & $2.58 \pm 1.55$ \\
\hline Cronbach's $\alpha(n)$ & $0.802(443)$ & $0.820(380)$ & $0.847(285)$ \\
\hline Personal strength & $2.86 \pm 1.59$ & $2.90 \pm 1.54$ & $2.55 \pm 1.60$ \\
\hline Cronbach's $\alpha(n)$ & $0.829(448)$ & $0.766(377)$ & $0.813(292)$ \\
\hline Spiritual change & $1.73 \pm 1.67$ & $1.65 \pm 1.66$ & $1.40 \pm 1.55$ \\
\hline Cronbach's $\alpha(n)$ & $0.907(428)$ & $0.892(373)$ & $0.890(286)$ \\
\hline \multicolumn{4}{|l|}{ Time-varying measures } \\
\hline Age, years & $72.84 \pm 8.23$ & $74.48 \pm 8.29$ & $75.81 \pm 8.11$ \\
\hline Duration of widowhood, months & $36.85 \pm 15.65$ & $56.88 \pm 17.92$ & $71.71 \pm 19.02$ \\
\hline \multicolumn{4}{|l|}{ Financial situation, \% } \\
\hline Not enough money & 5 & 5 & 4 \\
\hline Enough money & 83 & 81 & 79 \\
\hline More than enough money & 12 & 14 & 17 \\
\hline \multicolumn{4}{|l|}{ Health, \% } \\
\hline $\mathrm{Bad}$ & 3 & 3 & 3 \\
\hline So-so & 26 & 25 & 27 \\
\hline Good & 57 & 57 & 54 \\
\hline Very good & 14 & 15 & 16 \\
\hline Overcame loss, \% & 49 & 62 & 64 \\
\hline Repartnered, \% & 11 & 20 & 18 \\
\hline
\end{tabular}

Values are presented as mean $\pm \mathrm{SD}$, unless indicated otherwise. Personal growth was rated on a scale from 0 to 5 with higher values indicating more growth. 
(Table $3=$ p. 349)

Table 3. Sample composition by social support and embeddedness at entry into the sample $(n=508)$

\begin{tabular}{|c|c|c|c|c|c|}
\hline \multirow[b]{2}{*}{ Group-specific indicators: } & \multicolumn{3}{|c|}{ Loss-related support seeking } & \multicolumn{2}{|c|}{ Social embeddedness } \\
\hline & $\begin{array}{l}\text { G0: Coped } \\
\text { alone } \\
(n=102)\end{array}$ & $\begin{array}{l}\text { G1: Network } \\
\text { support seeking } \\
(n=117)\end{array}$ & $\begin{array}{l}\text { G2: Mixed } \\
\text { support seeking } \\
(n=289)\end{array}$ & $\begin{array}{l}\text { G0: Weakly } \\
\text { embedded } \\
(n=260)\end{array}$ & $\begin{array}{l}\text { G1: Strongly } \\
\text { embedded } \\
(n=248)\end{array}$ \\
\hline \multicolumn{6}{|l|}{ Dependent variables } \\
\hline Personal growth & $2.20 \pm 1.40$ & $2.82 \pm 1.15$ & $2.54 \pm 1.27$ & $2.46 \pm 1.25$ & $2.62 \pm 1.32$ \\
\hline Appreciation of life & $2.52 \pm 1.58$ & $3.34 \pm 1.33$ & $3.04 \pm 1.44$ & $2.88 \pm 1.39$ & $3.14 \pm 1.53$ \\
\hline Personal strength & $2.44 \pm 1.73$ & $3.17 \pm 1.38$ & $2.88 \pm 1.59$ & $2.76 \pm 1.54$ & $2.96 \pm 1.62$ \\
\hline Spiritual change & $1.45 \pm 1.65$ & $2.03 \pm 1.64$ & $1.77 \pm 1.67$ & $1.68 \pm 1.54$ & $1.85 \pm 1.78$ \\
\hline \multicolumn{6}{|l|}{ Explanatory variables } \\
\hline Age, years & $75.27 \pm 8.07$ & $72.73 \pm 8.95$ & $72.73 \pm 8.16$ & $72.92 \pm 8.40$ & $73.54 \pm 8.36$ \\
\hline \multicolumn{6}{|l|}{ Age at partner loss, $\%$} \\
\hline $50-74$ years & 63 & 68 & 71 & 69 & 69 \\
\hline 75 years and older & 37 & 32 & 29 & 31 & 31 \\
\hline Female, \% & 52 & 68 & 57 & 56 & 62 \\
\hline Duration of widowhood, months & $37.24 \pm 15.15$ & $35.47 \pm 17.00$ & $35.07 \pm 16.40$ & $35.43 \pm 16.29$ & $35.75 \pm 16.32$ \\
\hline \multicolumn{6}{|l|}{ Duration of widowhood, \% } \\
\hline 0-24 months & 21 & 23 & 24 & 25 & 22 \\
\hline $25-48$ months & 53 & 56 & 53 & 52 & 54 \\
\hline $49-60$ months & 21 & 14 & 20 & 18 & 20 \\
\hline 61-96 months & 5 & 7 & 3 & 5 & 4 \\
\hline Quality of marriage & $7.25 \pm 2.06$ & $7.60 \pm 1.89$ & $7.35 \pm 1.88$ & $7.15 \pm 2.06$ & $7.61 \pm 1.75$ \\
\hline Loss came unexpected, \% & 37 & 37 & 41 & 41 & 38 \\
\hline \multicolumn{6}{|l|}{ Education, $\%$} \\
\hline Primary & 12 & 14 & 13 & 11 & 16 \\
\hline Secondary & 58 & 58 & 55 & 57 & 55 \\
\hline Tertiary & 30 & 28 & 32 & 32 & 29 \\
\hline \multicolumn{6}{|l|}{ Financial situation, $\%$} \\
\hline Not enough money & 6 & 4 & 7 & 6 & 5 \\
\hline Enough money & 84 & 80 & 81 & 81 & 82 \\
\hline More than enough money & 10 & 16 & 12 & 13 & 13 \\
\hline \multicolumn{6}{|l|}{ Health, $\%$} \\
\hline Bad & 8 & 1 & 3 & 4 & 2 \\
\hline So-so & 30 & 29 & 23 & 30 & 22 \\
\hline Good & 43 & 59 & 61 & 56 & 59 \\
\hline Very good & 18 & 11 & 13 & 10 & 17 \\
\hline Overcame loss, $\%$ & 53 & 50 & 47 & 42 & 55 \\
\hline Repartnered, \% & 10 & 9 & 12 & 12 & 10 \\
\hline \multicolumn{6}{|c|}{ Additionally (for descriptive purpose only) } \\
\hline Duration of marriage, years & $42.27 \pm 11.14$ & $43.13 \pm 11.54$ & $43.42 \pm 10.32$ & $41.75 \pm 11.31$ & $44.43 \pm 10.07$ \\
\hline Retired, \% & 88 & 78 & 82 & 82 & 83 \\
\hline
\end{tabular}

Values are presented as mean $\pm S D$, unless indicated otherwise. Quality of marriage was rated on a scale from 0 to 9 with higher values indicating a higher relationship quality. Personal growth was rated on a scale from 0 to 5 with higher values indicating more growth. 
Table 4 (= p. 350)

Table 4. Personal growth trajectories over widowhood duration: empty models

\begin{tabular}{|c|c|c|c|c|}
\hline & $\begin{array}{l}\text { Model } 1 \\
\text { Personal growth }\end{array}$ & $\begin{array}{l}\text { Model } 2 \\
\text { Appreciation of life }\end{array}$ & $\begin{array}{l}\text { Model } 3 \\
\text { Personal strength }\end{array}$ & $\begin{array}{l}\text { Model } 4 \\
\text { Spiritual change }\end{array}$ \\
\hline \multicolumn{5}{|c|}{ Unconstrained model: Initial growth level unknown (data) } \\
\hline Unstandardized coefficients & $\mathrm{FE}$ & $\mathrm{FE}$ & $\mathrm{RE}$ & $\mathrm{RE}$ \\
\hline \multicolumn{5}{|l|}{ Duration of widowhood (years) } \\
\hline Linear time effect (time) & $-0.23(0.10)^{*}$ & $-0.30(0.12)^{*}$ & $-0.14(0.11)$ & $-0.20(0.10)$ \\
\hline Quadratic term $\left(t i m e^{2}\right)$ & $0.05(0.03)$ & $0.05(0.04)$ & $0.05(0.03)$ & $0.05(0.03)$ \\
\hline Cubic term $\left(\right.$ time $\left.^{3}\right)$ & $-0.00(0.00)$ & $-0.00(0.00)$ & $-0.00(0.00)$ & $-0.01(0.00)$ \\
\hline Intercept (first year) & $2.77(0.11)^{* * *}$ & $3.28(0.14)^{* * *}$ & $2.93(0.12)^{* * *}$ & $1.92(0.13)^{* * *}$ \\
\hline \multicolumn{5}{|l|}{ Model-fit and Hausman test } \\
\hline Number of observations & 1,119 & 1,108 & 1,117 & 1,087 \\
\hline$R^{2}$ (within) & 0.037 & 0.030 & 0.021 & 0.020 \\
\hline Hausman $p$ value & 0.038 & 0.001 & 0.177 & 0.715 \\
\hline \multicolumn{5}{|c|}{ Constrained model: Initial growth level set to zero } \\
\hline Unstandardized coefficients & $\mathrm{RE}$ & $\mathrm{RE}$ & $\mathrm{RE}$ & $\mathrm{RE}$ \\
\hline \multicolumn{5}{|l|}{ Duration of widowhood (years) } \\
\hline Linear time effect (time) & $2.74(0.15)$ & $3.18(0.19)^{* * *}$ & $3.29(0.19)^{* * *}$ & $1.83(0.20)^{* * *}$ \\
\hline Quadratic term $\left(\right.$ time $\left.e^{2}\right)$ & $-1.00(0.09)^{* * *}$ & $-1.16(0.11)^{* * *}$ & $-1.21(0.11)^{* * *}$ & $-0.66(0.11)^{* * *}$ \\
\hline Cubic term $\left(\right.$ time $\left.^{3}\right)$ & $0.14(0.02)^{* * *}$ & $0.17(0.02)^{* * *}$ & $0.18(0.02)^{* * *}$ & $0.09(0.02)^{* * *}$ \\
\hline Quadric term $\left(\right.$ time $\left.^{4}\right)$ & $-0.01(0.00)^{* * *}$ & $-0.01(0.00)^{* * *}$ & $-0.01(0.00)^{* * *}$ & $-0.01(0.00)^{* * *}$ \\
\hline Intercept & $0.09(0.02)^{* * *}$ & $0.10(0.02)^{* * *}$ & $0.10(0.02)^{* * *}$ & $0.07(0.02)^{* * *}$ \\
\hline \multicolumn{5}{|l|}{ Model-fit and Hausman test } \\
\hline Number of observations & 1,627 & 1,616 & 1,625 & 1,595 \\
\hline$R^{2}$ (within) & 0.647 & 0.620 & 0.617 & 0.372 \\
\hline Hausman $p$ value & 0.527 & 0.098 & 0.661 & 0.792 \\
\hline
\end{tabular}

${ }^{*} p<0.05 .{ }^{* *} p<0.01 .{ }^{* * *} p<0.001$.

\section{Results}

\section{Descriptive Statistics}

Table 2 provides sample characteristics from a longitudinal perspective, and Table 3 gives an overview of the sample composition by loss-related support seeking and embeddedness at baseline.

Values of PG seemed to decrease over time, whereby the amount of decline varied across the subdimensions of PG. Average ratings were lowest for spiritual change and highest for appreciation of life(Table 2). Because we analyzed the same sample of older widowers at all 3 waves, we had a consistent sample with rather little variation in age, financial situation, and even self-rated health over $(\leftarrow \mathbf{p . 3 5 0})$ time. However, we observed more within-variation in current grieving and repartnering. Nearly half of the respondents reported to have already overcome the loss of their spouse at baseline. Within the next 4 years, this percentage increased to $64 \%$. Only $11 \%$ had a new partner at baseline; this percentage was higher at Waves 2 and 3 with 20 and 18\%, respectively. 
(Table $5=$ p. 351)

Table 5. Personal growth group-specific trajectories over widowhood duration: empty models

\begin{tabular}{|c|c|c|c|c|}
\hline & $\begin{array}{l}\text { Model } 1 \\
\text { Personal growth }\end{array}$ & $\begin{array}{l}\text { Model } 2 \\
\text { Appreciation of life }\end{array}$ & $\begin{array}{l}\text { Model } 3 \\
\text { Personal strength }\end{array}$ & $\begin{array}{l}\text { Model } 4 \\
\text { Spiritual change }\end{array}$ \\
\hline \multicolumn{5}{|l|}{ Loss-related support seeking } \\
\hline Unstandardized coefficients & $\mathrm{RE}$ & $\mathrm{RE}$ & $\mathrm{RE}$ & $\mathrm{RE}$ \\
\hline Group 0: Coped alone (Ref.) & - & - & - & \\
\hline Group 1: Network support & $0.26(0.34)$ & $0.59(0.39)$ & $0.21(0.45)$ & $0.38(0.39)$ \\
\hline Group 2: Mixed support & $0.22(0.29)$ & $0.69(0.32)^{*}$ & $0.17(0.40)$ & $-0.08(0.38)$ \\
\hline \multicolumn{5}{|l|}{ Interactions as nested effects } \\
\hline Time ${ }^{*}$ Coped alone & $-0.20(0.18)$ & $0.10(0.25)$ & $-0.41(0.26)$ & $-0.40(0.26)$ \\
\hline Time ${ }^{*}$ Network support & $0.08(0.20)$ & $0.18(0.28)$ & $0.24(0.27)$ & $-0.36(0.26)$ \\
\hline Time ${ }^{*}$ Mixed support & $-0.19(0.13)$ & $-0.18(0.14)$ & $-0.19(0.15)$ & $-0.13(0.15)$ \\
\hline Time $e^{2 *}$ Coped alone & $0.02(0.06)$ & $-0.04(0.09)$ & $0.10(0.08)$ & $0.08(0.08)$ \\
\hline Time $e^{2 *}$ Network support & $-0.02(0.06)$ & $-0.04(0.08)$ & $-0.05(0.08)$ & $0.12(0.08)$ \\
\hline Time $e^{2 *}$ Mixed support & $0.05(0.04)$ & $0.03(0.04)$ & $0.07(0.04)$ & $0.03(0.04)$ \\
\hline Time $e^{3 *}$ Coped alone & $-0.00(0.00)$ & $0.00(0.00)$ & $-0.01(0.00)$ & $-0.01(0.00)$ \\
\hline Time ${ }^{3 *}$ Network support & $-0.00(0.00)$ & $0.00(0.00)$ & $0.00(0.00)$ & $-0.01(0.00)^{*}$ \\
\hline Time $e^{3 *}$ Mixed support & $-0.00(0.00)$ & $-0.00(0.00)$ & $-0.01(0.00)^{*}$ & $-0.00(0.00)$ \\
\hline Intercept (first year) & $2.45(0.26)^{* * *}$ & $2.43(0.26)^{* * *}$ & $2.79(0.34)^{* * *}$ & $1.90(0.34)^{* * *}$ \\
\hline \multicolumn{5}{|l|}{ Model-fit and test for path differences } \\
\hline Number of observations & 1,119 & 1,108 & 1,117 & 1,087 \\
\hline$R^{2}$ (within) & 0.042 & 0.026 & 0.031 & 0.037 \\
\hline$R^{2}$ (between) & 0.034 & 0.033 & 0.042 & 0.017 \\
\hline Test for path differences (all) ( $p$ value) & 0.290 & 0.756 & 0.409 & $0.021^{*}$ \\
\hline \multicolumn{5}{|l|}{ Social embeddedness } \\
\hline Unstandardized coefficients & $\mathrm{RE}$ & $\mathrm{RE}$ & $\mathrm{RE}$ & $\mathrm{RE}$ \\
\hline Group 1: Strongly embedded & $0.38(0.21)$ & $0.38(0.23)$ & $0.29(0.25)$ & $0.58(0.26)^{*}$ \\
\hline \multicolumn{5}{|l|}{ Interactions as nested effects } \\
\hline Time ${ }^{*}$ Weakly embedded & $0.03(0.11)$ & $0.07(0.14)$ & $-0.03(0.14)$ & $0.09(0.15)$ \\
\hline Time $*$ Strongly embedded & $-0.28(0.14)^{*}$ & $-0.19(0.16)$ & $-0.23(0.16)$ & $-0.42(0.17)^{* *}$ \\
\hline Time $e^{2 *}$ Weakly embedded & $-0.03(0.03)$ & $-0.06(0.04)$ & $0.00(0.04)$ & $-0.04(0.04)$ \\
\hline Time $e^{2 *}$ Strongly embedded & $0.08(0.04)$ & $0.05(0.05)$ & $0.09(0.05)$ & $0.11(0.05)^{*}$ \\
\hline Time $e^{3 *}$ Weakly embedded & $0.00(0.00)$ & $0.01(0.00)^{*}$ & $-0.00(0.00)$ & $0.00(0.00)$ \\
\hline Time $^{3 *}$ Strongly embedded & $-0.01(0.00)^{*}$ & $-0.01(0.00)$ & $-0.01(0.00)^{*}$ & $-0.01(0.00)^{*}$ \\
\hline Intercept (first year) & $2.44(0.14)^{* * *}$ & $2.81(0.15)^{* * *}$ & $2.77(0.18)^{* * *}$ & $1.60(0.18)^{* * *}$ \\
\hline \multicolumn{5}{|l|}{ Model-fit } \\
\hline Number of observations & 1,119 & 1,108 & 1,117 & 1,087 \\
\hline$R^{2}$ (within) & 0.047 & 0.039 & 0.024 & 0.042 \\
\hline$R^{2}$ (between) & 0.003 & 0.002 & 0.011 & 0.002 \\
\hline Test for path differences (all) ( $p$ value) & 0.056 & $0.029^{*}$ & 0.363 & $0.042^{*}$ \\
\hline
\end{tabular}

Table 3 shows that respondents who coped alone were on average 2.5 years older than those who sought network or mixed support, and they lost their partner more frequently in older age, i.e., $75+$ years (37\% vs. $32 \%$ and 29\%). Individuals with good self-rated health sought primarily network support rather than coping alone (61\% and 59\% vs. $42 \%$ ). However, solitary copers reported to be both more often in bad health ( $8 \%$ vs. $1 \%$ and $3 \%$ ) and in very good health (18\% vs. $11 \%$ and $13 \%)$ compared to those who sought network support. The associations be- tween the 3 types of support seeking and educational attainment, $(\leftarrow$ p. 351) their financial situation, marital quality, repartnering, and grieving were not statistically significant and indicated homogeneous groups. Similarhealth patterns emerged for perceived social embeddedness: strongly embedded respondents were more likely to be healthier (17\% vs. $10 \%)$ than their counterparts. They were also more likely to have mentally overcome the loss (55\% vs. $42 \%)$ and reported to have had a significantly higher- quality 
marriage before the loss (7.61 vs. 7.15). We observed nodifferencesinage, whethertheloss was expected $(\leftarrow$ p. 352) or not, education, financial situation, and repartnering between these 2 groups. Finally, widows reported more frequently to be strongly embedded (62\%) and to seek network support (68\%) than men.

(Table $6=$ p. 352)

Table 6. Personal growth group-specific trajectories by loss-related support seeking: full model

\begin{tabular}{|c|c|c|c|c|}
\hline & $\begin{array}{l}\text { Model } 1 \\
\text { Personal growth }\end{array}$ & $\begin{array}{l}\text { Model } 2 \\
\text { Appreciation of life }\end{array}$ & $\begin{array}{l}\text { Model } 3 \\
\text { Personal strength }\end{array}$ & $\begin{array}{l}\text { Model } 4 \\
\text { Spiritual change }\end{array}$ \\
\hline \multicolumn{5}{|c|}{ Step 1: Model with time-invariant covariates (duration $=0$ ) } \\
\hline Unstandardized coefficients & RE & $\mathrm{RE}$ & $\mathrm{RE}$ & $\mathrm{RE}$ \\
\hline Group 1: Network support & $0.35(0.34)$ & $0.79(0.40)^{*}$ & $0.23(0.41)$ & $0.50(0.44)$ \\
\hline Group 2: Mixed support & $0.31(0.31)$ & $0.83(0.32)^{* *}$ & $0.25(0.37)$ & $0.05(0.41)$ \\
\hline \multicolumn{5}{|l|}{ Interactions as nested effects } \\
\hline Time ${ }^{*}$ Coped alone & $-0.17(0.21)$ & $0.22(0.26)$ & $-0.36(0.27)$ & $-0.41(0.31)$ \\
\hline Time ${ }^{*}$ Network support & $0.08(0.21)$ & $0.11(0.27)$ & $0.24(0.25)$ & $-0.36(0.24)$ \\
\hline Time ${ }^{*}$ Mixed support & $-0.21(0.12)$ & $-0.23(0.14)$ & $-0.20(0.14)$ & $-0.12(0.16)$ \\
\hline Time $^{2} *$ Coped alone & $0.01(0.06)$ & $-0.08(0.09)$ & $0.09(0.08)$ & $0.08(0.09)$ \\
\hline Time $e^{2 *}$ Network support & $-0.01(0.07)$ & $-0.03(0.08)$ & $-0.05(0.08)$ & $0.12(0.07)$ \\
\hline Time $e^{2}$ Mixed support & $0.06(0.04)$ & $0.04(0.04)$ & $0.08(0.04)$ & $0.03(0.05)$ \\
\hline Time $^{3 *}$ Coped alone & $-0.00(0.00)$ & $0.01(0.01)$ & $-0.01(0.00)$ & $-0.01(0.00)$ \\
\hline Time $e^{3}$ Network support & $-0.00(0.00)$ & $0.00(0.00)$ & $0.00(0.00)$ & $-0.01(0.00)^{*}$ \\
\hline Time $^{3} *$ Mixed support & $-0.00(0.00)$ & $-0.00(0.00)$ & $-0.01(0.00)^{*}$ & $-0.00(0.00)$ \\
\hline \multicolumn{5}{|l|}{ Time-invariant covariates } \\
\hline Female & $-0.02(0.10)$ & $-0.20(0.12)$ & $0.15(0.12)$ & $0.01(0.14)$ \\
\hline Age at widowhood (only step 1) & $0.03(0.11)$ & $0.17(0.13)$ & $-0.06(0.13)$ & $0.36(0.16)^{*}$ \\
\hline Marital satisfaction & $-0.02(0.02)$ & $-0.04(0.03)$ & $0.00(0.03)$ & $0.03(0.03)$ \\
\hline Unexpected death & $-0.20(0.10)^{*}$ & $-0.18(0.12)$ & $-0.26(0.12)^{*}$ & $-0.11(0.14)$ \\
\hline Primary education $^{\mathrm{a}}$ & $0.26(0.17)$ & $0.24(0.18)$ & $0.12(0.18)$ & $0.42(0.21)^{*}$ \\
\hline Tertiary education ${ }^{\mathrm{a}}$ & $-0.56(0.11)^{* * *}$ & $-0.54(0.13)^{* * *}$ & $-0.60(0.14)^{* * *}$ & $-0.44(0.15)^{* *}$ \\
\hline \multicolumn{5}{|l|}{ Model-fit and test for path differences } \\
\hline Number of observations & 1,099 & 1,088 & 1,096 & 1,067 \\
\hline$R^{2}$ (within) & 0.042 & 0.022 & 0.030 & 0.040 \\
\hline$R^{2}$ (between) & 0.112 & 0.092 & 0.100 & 0.069 \\
\hline Test for path differences (all) ( $p$ value) & 0.470 & 0.642 & 0.317 & $0.024^{*}$ \\
\hline \multicolumn{5}{|l|}{ Step 2: Model with time-varying covariates } \\
\hline Age (linear) & $0.01(0.00)$ & $0.01(0.01)$ & $0.01(0.01)$ & $0.02(0.00)^{* *}$ \\
\hline Not enough money ${ }^{b}$ & $-0.06(0.22)$ & $-0.06(0.26)$ & $-0.33(0.25)$ & $-0.14(0.28)$ \\
\hline More than enough money ${ }^{b}$ & $-0.23(0.10)^{*}$ & $-0.34(0.13)^{* *}$ & $-0.15(0.14)$ & $-0.22(0.12)$ \\
\hline Bad health ${ }^{c}$ & $-0.51(0.23)^{*}$ & $-0.56(0.27)^{*}$ & $-0.25(0.32)$ & $-0.54(0.29)$ \\
\hline So-so health ${ }^{c}$ & $-0.09(0.09)$ & $0.08(0.12)$ & $-0.26(0.10)^{* *}$ & $-0.08(0.12)$ \\
\hline Very good health ${ }^{c}$ & $0.02(0.10)$ & $-0.03(0.15)$ & $0.04(0.14)$ & $0.07(0.13)$ \\
\hline Overcame loss & $-0.03(0.09)$ & $-0.13(0.11)$ & $0.02(0.12)$ & $-0.01(0.12)$ \\
\hline Repartnered & $0.03(0.12)$ & $0.16(0.15)$ & $0.04(0.15)$ & $-0.01(0.14)$ \\
\hline \multicolumn{5}{|l|}{ Model-fit and test for path differences } \\
\hline Number of observations & 1,031 & 1,021 & 1,030 & 1,003 \\
\hline$R^{2}$ (within) & 0.051 & 0.026 & 0.046 & 0.048 \\
\hline$R^{2}$ (between) & 0.111 & 0.101 & 0.099 & 0.071 \\
\hline Test for path differences (all) ( $p$ value) & 0.781 & 0.847 & 0.081 & $0.044^{*}$ \\
\hline
\end{tabular}

All effects that change from significant into nonsignificant between step 1 and step 2 are marked grey. Reference categories: ${ }^{\mathrm{a}}$ secondary education; ${ }^{b}$ enough money; ${ }^{c}$ good health. ${ }^{*} p<0.05 .{ }^{* *} p<0.01 .{ }^{* * *} p<0.001$. 
(Table $7=$ p. 353)

Table 7. Personal growth group-specific trajectories by social embeddedness: full model

\begin{tabular}{|c|c|c|c|c|}
\hline & $\begin{array}{l}\text { Model } 1 \\
\text { Personal growth }\end{array}$ & $\begin{array}{l}\text { Model } 2 \\
\text { Appreciation of life }\end{array}$ & $\begin{array}{l}\text { Model } 3 \\
\text { Personal strength }\end{array}$ & $\begin{array}{l}\text { Model } 4 \\
\text { Spiritual change }\end{array}$ \\
\hline \multicolumn{5}{|c|}{ Step 1: Model with time-invariant covariates (duration $=0$ ) } \\
\hline Unstandardized coefficients & RE & $\mathrm{RE}$ & $\mathrm{RE}$ & $\mathrm{RE}$ \\
\hline Group 1: Strongly embedded & $0.38(0.22)$ & $0.41(0.24)$ & $0.27(0.25)$ & $0.56(0.26)^{*}$ \\
\hline \multicolumn{5}{|l|}{ Interactions as nested effects } \\
\hline Time * Weakly embedded & $0.03(0.13)$ & $0.07(0.13)$ & $-0.02(0.15)$ & $0.11(0.15)$ \\
\hline Time $*$ Strongly embedded & $-0.29(0.14)^{*}$ & $-0.25(0.17)$ & $-0.22(0.17)$ & $-0.41(0.17)^{*}$ \\
\hline Time $^{2}=$ Weakly embedded & $-0.03(0.04)$ & $-0.06(0.04)$ & $-0.00(0.05)$ & $-0.04(0.05)$ \\
\hline Time $^{2} *$ Strongly embedded & $0.09(0.04)^{*}$ & $0.07(0.05)$ & $0.09(0.05)$ & $0.11(0.05)^{*}$ \\
\hline Time $^{3} *$ Weakly embedded & $0.00(0.00)$ & $0.01(0.00)^{*}$ & $-0.00(0.00)$ & $0.00(0.00)$ \\
\hline Time $e^{3} *$ Strongly embedded & $-0.01(0.00)^{*}$ & $-0.01(0.00)$ & $-0.01(0.00)^{*}$ & $-0.01(0.00)^{*}$ \\
\hline \multicolumn{5}{|l|}{ Time-invariant covariates } \\
\hline Female & $0.01(0.10)$ & $-0.16(0.12)$ & $0.18(0.13)$ & $0.05(0.14)$ \\
\hline Age at widowhood (only step 1) & $0.00(0.11)$ & $-0.20(0.13)$ & $-0.09(0.13)$ & $0.34(0.16)^{*}$ \\
\hline Marital satisfaction & $-0.01(0.02)$ & $-0.03(0.03)$ & $0.01(0.03)$ & $0.03(0.03)$ \\
\hline Unexpected death & $-0.21(0.10)^{*}$ & $-0.18(0.12)$ & $-0.25(0.13)^{*}$ & $-0.13(0.14)$ \\
\hline Primary education ${ }^{\mathrm{a}}$ & $0.24(0.16)$ & $0.22(0.18)$ & $0.11(0.18)$ & $0.40(0.22)$ \\
\hline Tertiary education ${ }^{\mathrm{a}}$ & $-0.55(0.12)^{* * *}$ & $-0.54(0.14)^{* * * *}$ & $-0.59(0.15)^{* * *}$ & $-0.44(0.16)^{* *}$ \\
\hline \multicolumn{5}{|l|}{ Model-fit and test for path differences } \\
\hline Number of observations & 1,099 & 1,088 & 1,096 & 1,067 \\
\hline$R^{2}$ (within) & 0.045 & 0.036 & 0.023 & 0.043 \\
\hline$R^{2}$ (between) & 0.070 & 0.053 & 0.068 & 0.044 \\
\hline Test for path differences (all) ( $p$ value) & $0.045^{*}$ & $0.038^{*}$ & 0.299 & $0.049^{*}$ \\
\hline \multicolumn{5}{|l|}{ Step 2: Model with time-varying covariates } \\
\hline Age (linear) & $0.00(0.01)$ & $-0.02(0.01)^{*}$ & $0.00(0.01)$ & $0.02(0.01)^{* *}$ \\
\hline Not enough money ${ }^{b}$ & $-0.03(0.22)$ & $-0.03(0.29)$ & $-0.28(0.25)$ & $-0.13(0.27)$ \\
\hline More than enough money ${ }^{b}$ & $-0.20(0.10)^{*}$ & $-0.31(0.14)^{*}$ & $-0.11(0.15)$ & $-0.21(0.13)$ \\
\hline Bad health ${ }^{c}$ & $-0.72(0.21)^{* * *}$ & $-0.75(0.24)^{* * * *}$ & $-0.52(0.33)$ & $-0.69(0.29)^{*}$ \\
\hline So-so health ${ }^{c}$ & $-0.10(0.09)$ & $0.05(0.11)$ & $-0.27(0.11)^{*}$ & $-0.07(0.11)$ \\
\hline Very good health ${ }^{c}$ & $-0.01(0.10)$ & $-0.08(0.14)$ & $-0.01(0.14)$ & $0.10(0.12)$ \\
\hline Overcame loss & $-0.03(0.09)$ & $-0.16(0.11)$ & $0.02(0.12)$ & $0.01(0.13)$ \\
\hline Repartnered & $0.05(0.11)$ & $0.18(0.15)$ & $0.06(0.15)$ & $0.01(0.14)$ \\
\hline \multicolumn{5}{|l|}{ Model-fit and test for path differences } \\
\hline Number of observations & 1,031 & 1,021 & 1,030 & 1,003 \\
\hline$R^{2}$ (within) & 0.053 & 0.038 & 0.034 & 0.039 \\
\hline$R^{2}$ (between) & 0.074 & 0.074 & 0.068 & 0.052 \\
\hline Test for path differences (all) ( $p$ value) & 0.123 & $0.033^{*}$ & 0.307 & 0.220 \\
\hline
\end{tabular}

All effects that change from significant into nonsignificant between step 1 and step 2 are marked grey. Reference categories: ${ }^{\mathrm{a}}$ secondary education; ${ }^{\mathrm{b}}$ enough money; ${ }^{\mathrm{c}}$ good health. ${ }^{*} p<0.05 .{ }^{* *} p<0.01 .{ }^{* * *} p<0.001$.

\section{Overall Trajectory of $P G$}

Conceptually, PG is triggered by an event and its initial level is supposed to be zero. Our data, however, provided neither a comparison group (i.e., a group of married individuals without the experience of widowhood), nor any information about the very beginning of the process. Thus, we estimated 2 possible trajectories of PG over time - one with and one without a constraint regarding the beginning of the process (Fig. 1). The unconstrained model corresponds to our data, which indicated a moderate PG level already at event entry. The constrained mod- el was an attempt to estimate the trajectory of PG according to thenatural assumption ofazero 
level atevententry $(\leftarrow$ p. 353) based on an extended data set, which included an artificially added "Wave 0" (see also Table 4). Although the shape varied from a linear function to a sickle function, the trajectory after the first widowhood year was almost identical to a very stable, moderate level of PG (on aver- age, 2.5 scale points). Due to data limitations concerning the sparse number of observations on the tail ends of our observation window, we will subsequently focus on the time span between 2 and 7 years after partner loss when interpreting our results.

(Fig. 1 = p. 354)

Fig. 1. Personal

growth (PG)

trajectories:

unconstrained and

constrained model.

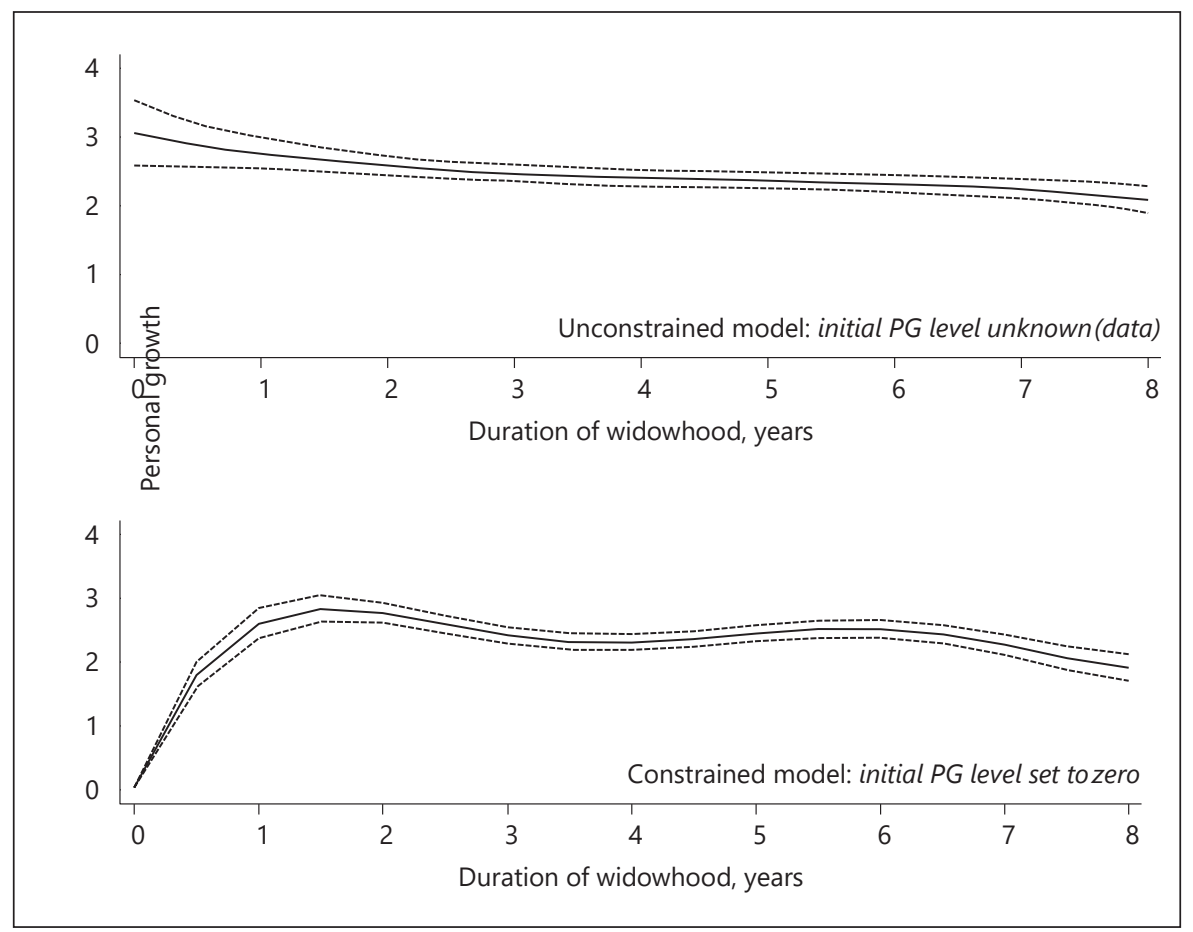

\section{Group-Specific Trajectories of PG: Empty Models}

$R^{2}$ within values for the group-specific trajectories of PG without any covariates (Table 5) indicated that individual changes within trajectories over time explained less than $5 \%$ of the variance of PG and its subdimensions - both in the models for loss-related support (2.6\% for appreciation of life and 3.7\% for spiritual change) and in the models for social embeddedness (2.4\% for person- al strength and $4.2 \%$ for spiritual change). Different types of loss-related support and social embeddedness (differences between individuals) explained up to $4.2 \%$ and $1.1 \%$ of the variance, respectively.

Group-specific trajectories of PG and their subdimensions seemed to be rather stable over time for two reasons. First, there was little temporal variation according to relatively low $R^{2}$ within values. Second, most group*time interaction terms for linear, quadratic, and cubic effects were not significant (i.e., technically, 
indicating a horizontal line), except for spiritual change for strongly embedded individuals (all 3 interactions were significant) and some cubic terms for other subdimensions of PG(see Interactions as nested effects in Table 5). However, the Wald test for differences in time paths indicated that the trajectories of appreciation of life differed significantly for weakly and strongly embedded respondents $(p=0.029)$, whereas the trajectories of spiritual change differed significantly for both loss-related social support seeking $(p=0.021)$ and the social embeddedness groups $(p=0.042)$.

\section{Trajectories of PG by Loss-Related Social Support Seeking}

Table 6 summarizes the results for growth curves by support seeking accounting for time-invariant covariates (Step 1), and additionally, for time-varying covariates (Step 2). Figures 2 and 4 illustrate the trajectories for each model.

The Wald test also indicated significantly different time paths for spiritual change across support seeking groups, even when adjusting for time-invariant covariates ( $p=0.024$ and $p=0.044)$. This should, however, $(\leftarrow$ p. 354) be interpreted with caution due to the strong concavity out- side of the trustworthy interval from the second to the seventh year of widowhood. Although the shape of PG and its subdimensions remained mostly flat over time, differences across the 3 support-seeking groups yielded aclear pattern. First, respondents who did not seek social support (solitary copers) had consistently the lowest scores and network support seekers the highest scores on all PG subdimensions. Second, the level differences in PG between those who coped alone and those who sought social support (network and mixed support seekers) were significant for almost all years. The differences between Group 1 (network support seekers) and 2 (mixed support seekers) were significant only at a middle stage of the be- reavement process (about 3-5 years), except for spiritual change where there were no significant differences. Third, seeking solely network support appeared to foster PG (overall rating, personal strength, and appreciation of life) during the first 3 years after the loss of the spouse. 
(Fig. 2. = p. 355)

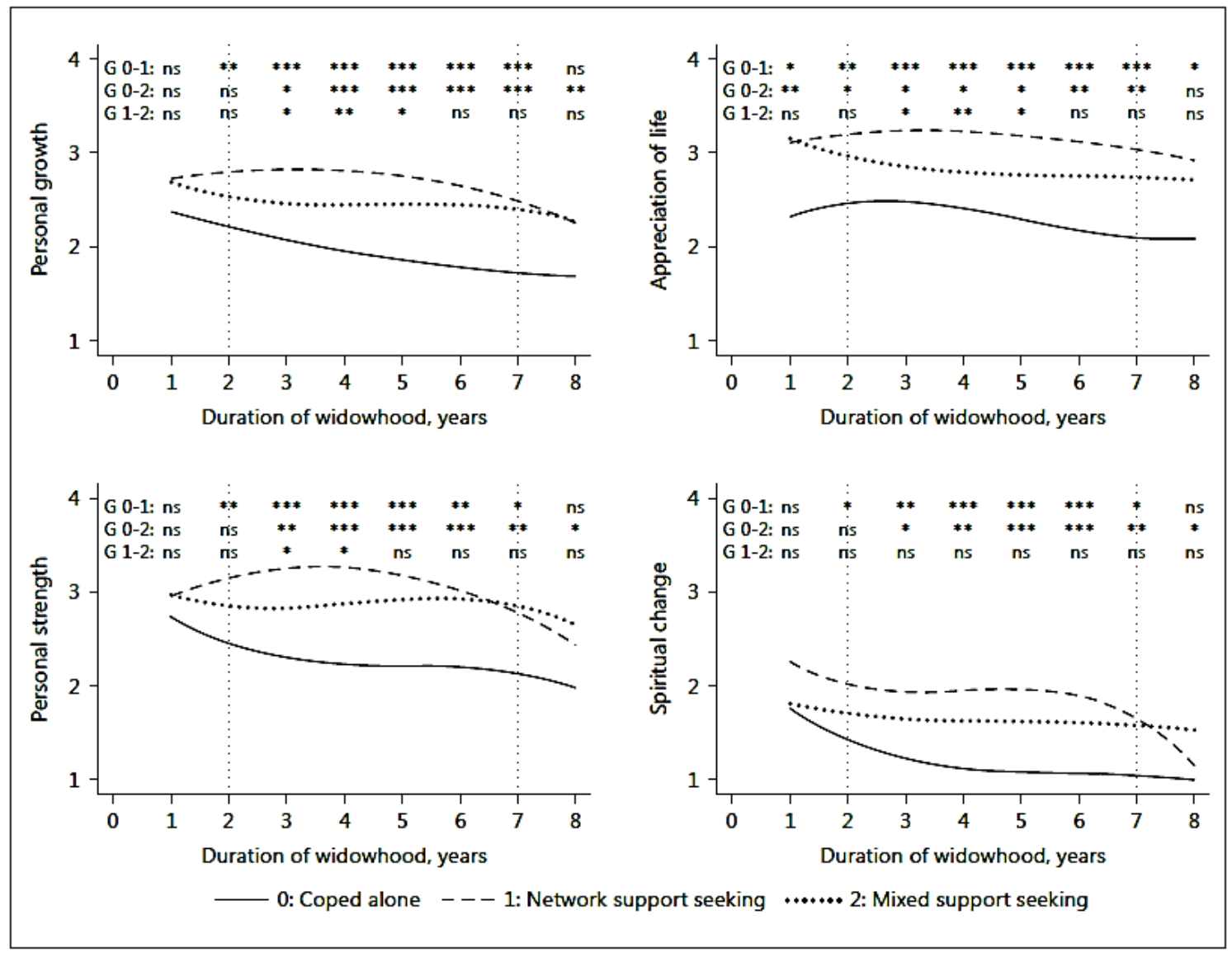

Fig. 2. Personal growth trajectories by social support over the duration of widowhood (Step 1: time-invariant covariates).

However, this effect seemed to vanish in the long run, whereas the combination of network support seeking and coping alone (mixed support seekers) appeared to have the most stable effect on PG over time.

Trajectories by social support seeking did not change much after including time-varying covariates. Analyses revealed that tertiary education was an important predictor of PG and its subdimensions. Highly educated individuals were more likely to experience lower levels of PG than less educated individuals. Unexpected partner loss was associated with lower levels of PG and personal strength, whereas being older when becoming widowed and age were positively associated with spiritual change. Finally, self-rated health and respondents' financial situation seemed to play a key role in the bereavement process, especially for the appreciation of life and personal strength. Both health problems and, surprisingly, having more financial resources were associated with a decrease in PG. $(\leftarrow$ p. 355) 
(Fig. 3 = p. 356)

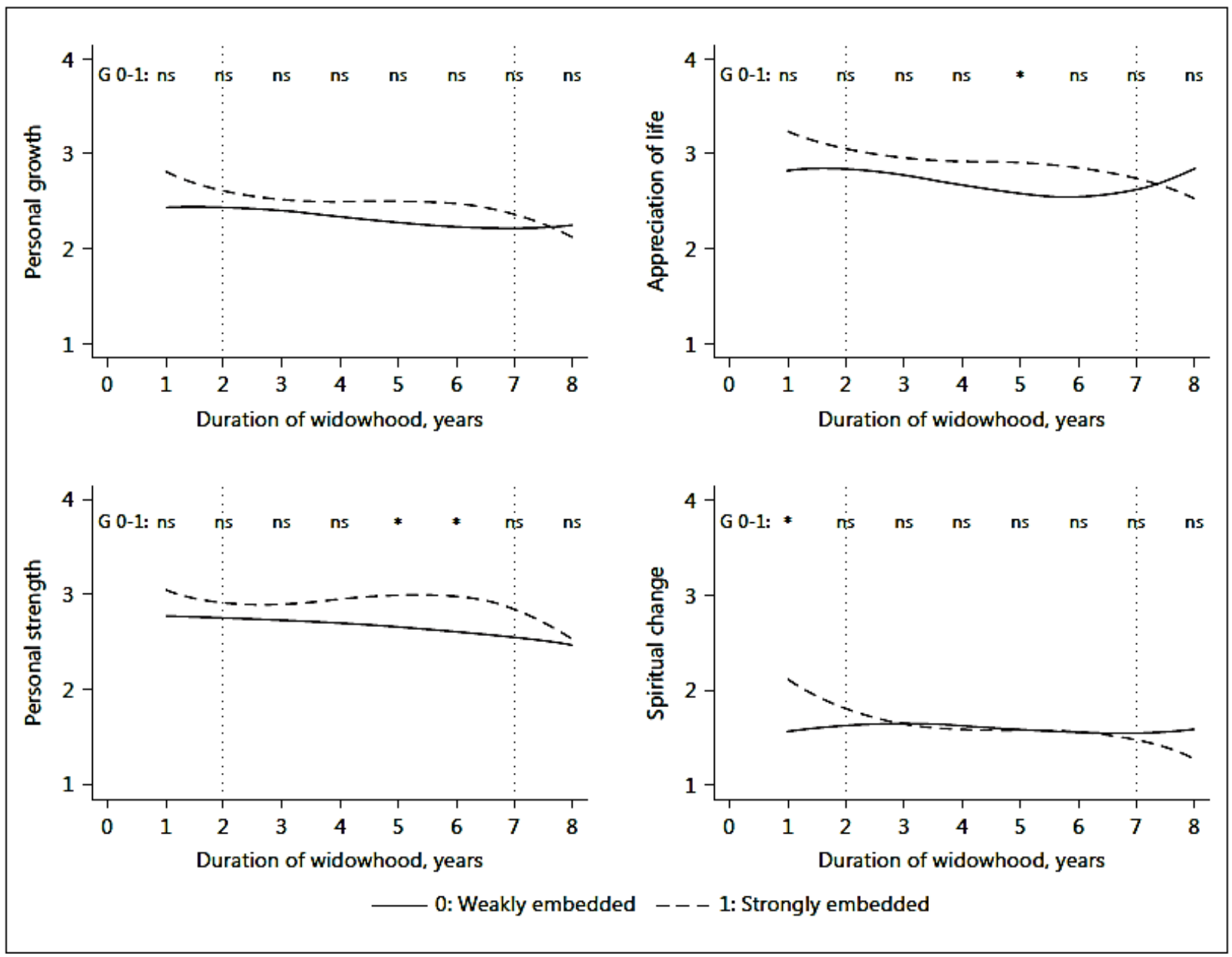

Fig. 3. Personal growth trajectories by social embeddedness over the duration of widowhood (Step 1: time-invariant covariates).

\section{Trajectories of PG by Social Embeddedness}

Table 7 summarizes the results for growth curves by perceived social embeddedness accounting for timeinvariant covariates (Step 1), and additionally, for time-varying covariates (Step 2; see Fig. 3 and 5, respectively). The trajectories of PG and their subdimensions by social embeddedness did not differ much over time, even if the $p$ value of the Wald test was below 0.05 for appreciation of life in the full model. Further, the AME did not show any significant differences in PG and its subdimensions, except for appreciation of life at Years 5-6 and personal strength at Year 5. Thus, the progression of PG did not vary for weakly or strongly embedded participants.

Trajectories by social embeddedness became even more similar to each other after including time-varying covariates. The analyses for social embeddedness showed exactly the same pattern of significant covariates for 
PG and its subdimensions as reported for our models by lossrelated social support. Gender, marital satisfaction, current grieving, and repartnering did not play a significant role for the trajectories of PG over time.

\section{Discussion}

Experiencing widowhood in old age is an age-normative, yet deeply disruptive transition that requires bereaved individuals to renegotiate social roles, restructure daily routines, and even recompose social networks $[1,10]$. Some studies, however, documented that overcoming critical transitions can stimulate PG in terms of gaining new perspectives on priorities in life or increased self- perceptions of strength [3,22,23]. The present study con- tributes and extends this line of work by examining trajectories of PG among a sample of individuals who lost their spouse after an average of 43 years of marriage. We assessed individuals' ratings of PG after about $2-3$ years $(\leftarrow$ p. 356) of spousal loss and then tracked their ratings for 4 years into the adjustment process.

(Fig. 4 = p. 357)

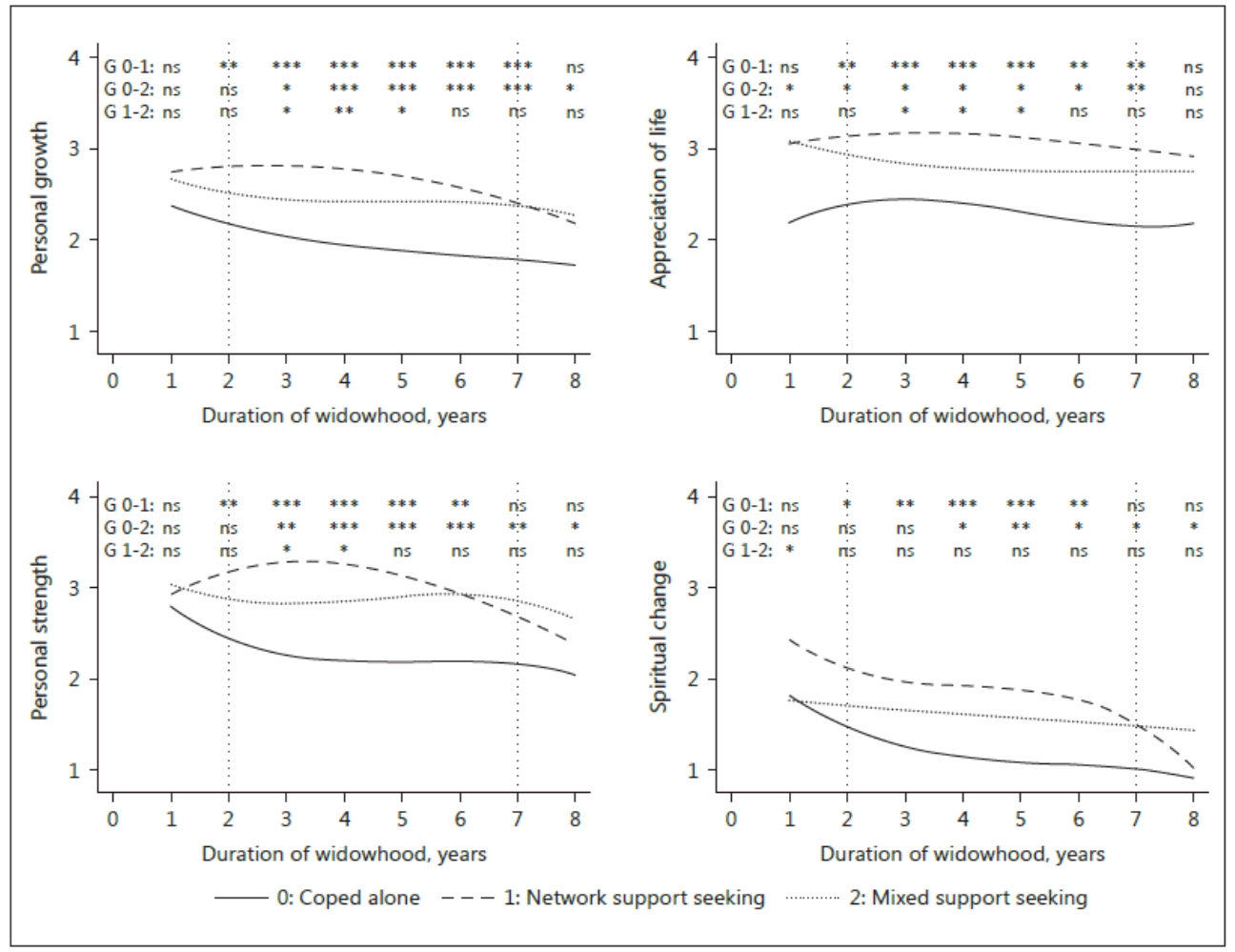

Fig. 4. Personal growth trajectories by social support over the duration of widowhood (Step 2: full model). 
In general, the trajectory of PG was relatively flat and stable on a medium level, which was against our expectation that PG would be more pronounced in the beginning and decreases over time. This could indicate that PGafter bereavement is not only a short-term coping strategy, but rather an accomplishment that is achieved and stabilized over a longer time period of adjusting to the loss [5,38]. Accounts of relatively stable trajectories in light of bereavement were also documented for other psychological constructs such as well-being for the majority of individuals [15], which mirrors our findings. Because most individuals adjust well to their new role as widow(er) [14], particularly during a time in life where this transition is rather normative and supporting networks may be larger compared to those who experience widowhood off-time, the potential for PG may be limited [6].

Because social support is an essential element of adjusting to critical life transitions such as widowhood $[10,13,23]$, we further examined the link between two aspects of social support and PG over time. Loss-related social support seeking was expected to be more instrumental to PG at earlier stages of becoming widowed, whereas a general sense of social embeddedness as the perception of having a broad supportive network readily available would foster PG in the long run. Partly in line with these expectations, loss-specific support seeking did indeed seem to foster overall ratings of PG, and appreciation of life, at the first wave of assessment. No differences in base- line ratings of PG and its subdimensions emerged between individuals with weak and strong social embeddedness. One could argue that having a strong social network in place may beless crucial for the emergence of PG in contrast to the process of proactively reaching out to key contacts for support and restructuring one's network accordingly to the needs of the new situation [9, 10]. More process-oriented information on the evolution of social networks throughout the transition, however, was not available in our data. $(\leftarrow$ p. 357)

Even though loss-related social support seeking seems to be the stronger predictor of PG, we did find significantly different trajectories of spiritual change for both support seeking and social embeddedness. In both cases, those who coped primarily alone or were weakly embedded into networks reported more growth on this dimension compared to those who also utilized networks or were embedded more strongly. This could indicate that engaging in or turning to spiritual or religious activities could be a strategy to compensate lacking social support and to attribute a higher meaning to the loss [10], even though evidence on the impact of spirituality on post- bereavement adjustment is mixed [24]. 


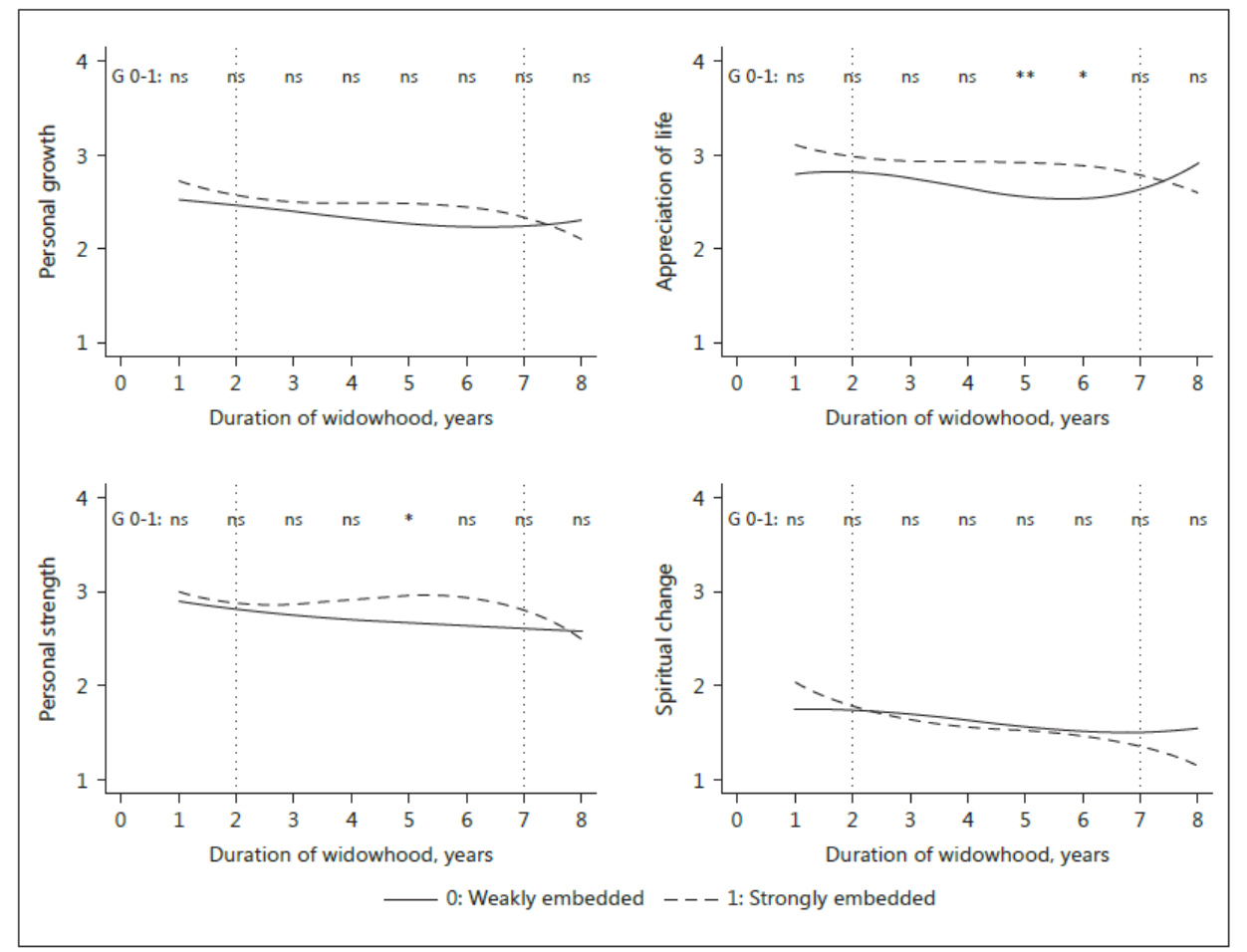

Fig. 5. Personal growth trajectories by social embeddedness over the duration of widowhood (Step 2: full model).

Although we did not specify hypotheses on the impact of our covariates, some interesting results emerged. For example, older participants consistently reported lower ratings of PG at baseline. This effect could be attributed to differences in cognitive capacities [38,39], but also age- related decreases in social networks and increasing health impairments [13]. Relatedly, healthier individuals reported higher ratings of PG because they may have had more chances to engage in social activities or to look for sup- port in light of the loss compared to their more severely impaired peers.

Interestingly, both the highest level of education and financial security were associated with lower levels of PG, which could be explained from two competing angles. From a stress-resiliency perspective, the less privileged may display more potential for PG because they may have more experience in dealing with and overcoming adverse events due to their cumulative exposure to stressors [4, 40]. Alternatively, we may observe a ceiling effect for PG among the most privileged because the PG scale explicitly assessed change in perceptions due to spousal loss rather than baseline ratings. It could be the case that this group may simply not change their habits and perceptions after becoming widowed as much as their more disadvantaged peers because they were already embedded into tighter social network and activities with or without their spouse due to greater financial resources and benefits $(\leftarrow \mathbf{p . ~ 3 5 8 )}$ tied to higher education (e.g., volunteering, leisure, or cultural activities). 


\section{Limitations and Future Outlook}

In this study, we only looked at two aspects of social support-loss-related support seeking and perceived social embeddedness. Both aspects were operationalized with items that captured predominantly cognitiveemotional types of support. We might have observed further variations in PG over time, particularly for social embeddedness, when looking at other aspects or functions of social support, such as support quality and satisfaction or changes in support networks and their composition. Un- fortunately, these indicators were not available in our data.

Second, our factor analyses revealed 3 dimensions, rather than 5, of PG for our sample of older widowers. Hence, we suggest that future research should pay close attention to the underlying factorial structure for the construct of PG in specific subpopulations, rather than treating it as a universal construct. Particularly for the older samples, it might be the case that some subdimensions are not as relevant as others (e.g., particularly "new possibilities" may be more important for younger age groups compared to older populations).

Lastly, from a conceptual standpoint, PG is triggered by an event and is therefore supposed to have an initial level of zero and increase after the event. Our study, how- ever, first assessed widowers about 3 years after having become widowed. Because we were not able to capture the initial increase in PG shortly after the event, our results point to rather flat trajectories of PG over time. Additionally, in the case oflong-termillnesses or caregiving for the deceased prior to the event, possible anticipation effects cannotbe entirely ruled out in the development of PG and are understudied.

Taken together, our study demonstrated, on average, a relatively stable and flat trajectory of PG on a moderate level for most participants who lost their spouse after a long-term marriage. Loss-related social support seeking, however, fostered some dimensions of PG-particularly during the earlier stages of adjusting to the new role as widow(er). Even though we used a unique, time-continuous strategy to model theimpact of social support on PG based on yearly data, future studies should expand this line of work by examining the longitudinal link between PG and social support on a finer time scale(e.g., monthly or daily measurements with diary studies). It is our hope that future research will replicate our findings for various normative and nonnormative life events across the life course, and using different scales and subdomains in the assessment of PG. 


\section{Acknowledgements}

This study was part of a national research project allocated to Pasqualina Perrig-Chiello. It was conducted in collaboration with the Swiss National Centre of Competence in Research LIVES - Overcoming Vulnerability: Life Course Perspectives, and the data used for this study has been funded by the Swiss National Science Foundation (grant No. 125770). The authors are grateful to the Swiss National Science Foundation for its financial assistance. The authors would also like to thank Dr. Oliver Arránz Becker and the anonymous reviewers for their insightful comments, which helped to improve the manuscript substantially. $(\leftarrow$ p. 359)

\section{References}

${ }^{1}$ Bennett KM, Soulsby LK: Wellbeing in bereavement and widowhood. Illn Crises Loss 2011;20:321337.

2 Zivin K, Christakis NA: The emotional toll of spousal morbidity and mortality. Am J Geriatr Psychiatry 2007;15:772-779.

${ }^{3}$ Helgeson VS, Reynolds KA, Tomich PL: A meta-analytic review of benefit finding and growth. J Consult Clin Psychol 2006;74:797-816.

${ }^{4}$ Stanton AL, Bower JE, Low CA: Posttraumatic growth after cancer; in Calhoun LG, Tedeschi R (eds): Handbook of Posttraumatic Growth: Research and Practice. New York, Psychological Press, 2006, pp 138-175.

${ }^{5}$ Studley B, Chung MC: Posttraumatic stress and well-being following relationship dissolution: coping, posttraumatic stress disorder symptoms from past trauma, and traumatic growth. J Loss Trauma 2015;20:317-335.

${ }^{6}$ Armstrong D, Shakespeare-Finch J: Relation- ship to the bereaved and perceptions of severity of trauma differentiate elements of post- traumatic growth. Omega (Westport) 2011; 63:125-140.

${ }^{7}$ Tashiro TY, Frazier P: "I'll never be in a relationship like that again": personal growth following romantic relationship breakups. Pers Relatsh 2003;10:113-128.

${ }^{8}$ Zoellner T, Maercker A: Posttraumatic growth in clinical psychology: a critical review and introduction of a two component model. Clin Psychol Rev 2006;26:626-653.

${ }^{9}$ Bookwala J, Marshall KI, Manning SW: Who needs a friend? Marital status transitions and physical health outcomes in later life. Health Psychology 2014;33:505-515.

${ }^{10}$ Hollstein B: Soziale Netzwerke nach der Verwitwung: Eine Rekonstruktion der Veränderungen informeller Beziehungen [Social Networks after Widowhood: A Reconstruction of Change in Informal Relationships]. Opladen, Leske + Budrich, 2002.

${ }^{11} \mathrm{Li} \mathrm{Y}$ : Recovering from spousal bereavement in later life: does volunteer participation play a role? J Gerontol B Psychol Sci Soc Sci 2007;62: 257-266.

${ }^{12}$ Utz RL, Reidy EB, Carr D, Nesse R, Wortman C: The daily consequences of widowhood: the role of gender and intergenerational transfers on subsequent housework performance. JFam Issues 2004;25:683-712.

${ }^{13}$ Stevens NL, Martina CM, Westerhof GJ: Meeting the need to belong: predicting effects of a friendship enrichment program for older women. Gerontologist 2006;46:495-502. 
${ }^{14}$ Spahni S, Morselli D, Perrig-Chiello P, Bennett KM: Patterns of psychological adaptation to spousal bereavement in old age. Gerontology 2015;61:456-468.

${ }^{15}$ Mancini AD, Bonanno GA, Clark AE: Stepping off the hedonic treadmill. J Individ Differ 2011;32:144-152.

${ }^{16}$ Martin LG: Demography \& aging; in Binstock RH, George LK (eds): Handbook of Aging and the Social Sciences. San Diego, Elsevier Academic Press, 2011, pp 33-56.

${ }^{17}$ Settersten RA Jr, Trauten ME: The new terrain of old age: hallmarks, freedoms, and risks; in Bengston VL, Gans D, Pulney N, Norella M, Silverstein M (eds): Handbook of Theories of Aging. New York, Springer, 2009, pp 455-469.

${ }^{18}$ Cheng ST, Chan AC: Relationship with others and life satisfaction in later life: do gender and widowhood make a difference? J Gerontol B Psychol Soc Sci 2006;61:46-53.

${ }^{19}$ Rossi NE, Bisconti TL, Bergeman C: The role of dispositional resilience in regaining life satisfaction after the loss of a spouse. Death Stud 2007;31:863-883.

${ }^{20}$ Zettel LA, Rook KS: Substitution and compensation in the social networks of older widowed women. Psychol Aging 2004;19:433- 443.

${ }^{21}$ Infurna FJ, Wiest M, Gerstorf D, Ram N, Schupp J, Wagner GG, Heckhausen J: Changes in life satisfaction when losing one's spouse: individual differences in anticipation, reaction, adaptation and longevity in the German Socio-Economic Panel Study (SOEP). Ageing Soc 2017;37:899-934.

${ }^{22}$ Tedeschi RG, Calhoun LG: Posttraumatic growth: conceptual foundations and empirical evidence. Psycholl Inq 2004;15:1-18.

${ }^{23}$ Currier JM, Holland JM, Neimeyer RA: Pro- longed grief symptoms and growth in the first 2 years of bereavement: evidence for a nonlinear association. Traumatology 2012;18:65- 71.

${ }^{24}$ Caserta M, Lund D, Utz R, De Vries B: Stress- related growth among the recently bereaved. Aging Ment Health 2009;13:463-476.

${ }^{25}$ Barskova T, Österreich R: Post-traumatic growth in people living with a serious medical condition and its relations to physical and mental health: a systematic review. Disabil Rehabil 2009;31:17091733.

${ }^{26}$ Bower JE, Low CA, Tedlie Moskowitz J, Sepah S, Epel E: Benefit finding and physical health: Positive psychological changes and enhanced allostasis. Soc Personal Psychol Compass 2008;2:223-244.

${ }^{27}$ Guiaux M, Van Tilburg T, Van Groenou MB: Changes in contact and support exchange in personal networks after widowhood. Pers Relatsh 2007;14:457-473.

${ }^{28}$ Michael C, Cooper M: Post-traumatic growth following bereavement: a systematic review of the literature. Couns Psychol Rev 2013;28:18- 33.

${ }^{29}$ Schaefer J, Moos R: The context for posttraumatic growth: life crises, individual and social resources, and coping; in Tedeschi RG, Park C, Calhoun L (eds): Posttraumatic Growth: Positive Changes in the Aftermath of Crisis. Mahwah, Erlbaum, 1998, pp 99-126.

${ }^{30}$ Prati G, Pietrantoni L: Optimism, social sup- port, and coping strategies as factors contributing to posttraumatic growth: a meta-analysis. J Loss Trauma 2009;14:364-388.

${ }^{31}$ Park CL, Cohen LH, Murch RL: Assessment and prediction of stress-related growth. J Personal 1996;64:71-105.

32 Milam JE, Ritt-Olson A, Unger JB: Post-traumatic growth among adolescents. J Adolesc Res 2004;19:192-204.

${ }^{33}$ Polatinsky S, Esprey Y: An assessment of gender differences in the perception of benefit resulting from the loss of a child. J Trauma Stress 2000;13:709-718.

${ }^{34}$ Cann A, Calhoun LG, Tedeschi RG, Taku K, Vishnevsky T, Triplett KN, Danhauer SC: A short form of the Posttraumatic Growth Inventory. Anxiety Stress Coping 2010;23:127-137.

${ }^{35}$ Skinner EA, Edge K, Altman J, Sherwood H: Searching for the structure of coping: a review and critique of category systems for classifying ways of coping. Psychol Bull 2003;129: 216-269. 
${ }^{36}$ Gierveld JDJ, Van Tilburg T: A 6-item scale for overall, emotional, and social loneliness confirmatory tests on survey data. Res Aging 2006;28:582-598.

${ }^{37}$ Singer JD, Willett JB: Applied Longitudinal Data Analysis: Modeling Change and Event Occurrence. Oxford, Oxford University Press, 2003.

${ }^{38}$ Znoj H: Bereavement and posttraumatic growth; in Calhoun LG, Tedeschi RG (eds): Handbook of Posttraumatic Growth: Research and Practice. New York, Psychology Press, 2006, pp 176-196.

${ }^{39}$ Charles ST: Strength and vulnerability integration: a model of emotional well-being across adulthood. Psychol Bull 2010; 136: 1068-1091.

${ }^{40}$ Chen E, Miller GE: "Shift-and-persist" strategies: why low socioeconomic status isn't always bad for health. Perspect Psychol Sci 2012;7:135-158. 